\title{
Razón colonial, imaginario de-colonial y feminismos: Nancy Morejón, Jamaica Kincaid y la construcción de la identidad cultural en la poética del caribe
}

\author{
Esther SÁNCHEZ-PARDO GONZÁLEZ \\ Universidad Complutense de Madrid \\ esanchez_pardo@filol.ucm.es
}

Recibido: Octubre 2015

Aceptado: Diciembre 2015

\section{RESUMEN}

Este artículo plantea un debate abierto sobre si el feminismo no occidental ha llegado a un momento histórico postcolonial en el que nuevas propuestas abran un horizonte para contrarrestar el devenir de la historia colonial y su legado patriarcal. El trabajo de autoras como Nancy Morejón (La Habana 1944-) y Jamaica Kincaid (St John’s, Antigua, 1949-) se propone inscribir a la mujer negra en la historia entendida como "contra-narrativa" a la historia patriarcal. Un análisis de sus planteamientos a la luz de teorías como la del imaginario decolonial, el pensamiento fronterizo y la reescritura de la historia revelan alternativas con proyección de futuro, emancipadoras para el feminismo del siglo XXI.

Palabras clave: proyecto de-colonial, Nancy Morejón, Jamaica Kincaid, poética del Caribe.

Colonial reason, de-colonial imaginary and feminisms: Nancy Morejón, Jamaica Kincaid and the construction of cultural identity in Caribbean poetics

\begin{abstract}
This paper raises the crucial question as to whether non-Western feminisms have reached a postcolonial historical moment in which new proposals and alternatives may open up a horizon of expectations to counter the development of colonial history and its patriarchal legacy. Engaged writers like Nancy Morejón (La Habana 1944-) and Jamaica Kincaid (St John’s Antigua, 1949-) set themselves up to make room for black women in history, a counternarrative to patriarchal History. An analysis of representative pieces of poetry and fiction by both writers in a dialogue with ideas such as the decolonial imaginary, border thinking and rewriting History shed light on alternatives for emancipatory feminist projects for the 21st century.
\end{abstract}

Keywords: Decolonial Project, Nancy Morejón, Jamaica Kincaid, Caribbean poetics. 


\section{INTRODUCCIÓN: FEMINISMOS Y PROYECTO DE-COLONIAL}

Este trabajo tiene por objeto mostrar cómo autoras como Nancy Morejón (Habana, 1944-) y Jamaica Kincaid (Antigua, 1949-) se proponen con sus textos deconstruir la idea de una historiografía lineal e ir más allá de las categorías tradicionales de la escritura de la historia para poner en tela de juicio las limitaciones de los discursos de la colonización. Ambas responden con creatividad y valentía a la historia oficial con nuevas maneras de contar y escribir su experiencia. Esta estrategia novedosa de fabricación histórico-literaria, desembocará, sin duda, en lo que hemos dado en llamar "imaginario de-colonial," un proceso en el que el sujeto puede activamente imaginar su propio futuro en función de sus circunstancias e intereses. Parcialmente también este estudio aspira a abordar la crítica que autoras como Morejón o Kincaid han dirigido a las categorías monolíticas de la raza y de la pertenencia a la nación, así como el efecto que todo ello ha tenido en su propio re-posicionamiento geográfico e ideológico en sus vidas. En mayor o menor medida ambas han puesto de manifiesto arquetipos de fuerza femenina que llegan a cuestionar y trascender las ideas de nación y raza.

Contamos ya con una tradición crítica que ha señalado que la colonialidad es el lado oscuro de la modernidad capitalista ${ }^{1}$. En el pensamiento latinoamericano contemporáneo este imaginario se constituye como el centro frente al cual se va imponiendo la "diferencia" colonial o la "exterioridad" respecto de él. La realidad afrocaribeña (en sus diferentes vertientes lingüísticas) ha sido articulada a partir de la imagen que Europa proyecta de su Otro. En la historia del pensamiento latinoamericano y caribeño desde el siglo XIX ha habido varios intentos de superar la dependencia cultural, la comparación con la cultura europea, la pretendida inferioridad latinoamericana frente al bastión de la alta cultura y la democracia a nivel global que Europa ha ostentado. La historia de toda esta área geográfica es la historia de la búsqueda de la "identidad", de un ideal por representarse desde sí mismos, y de la construcción de una imagen que dé cuenta de su ethos, de su papel cultural y geopolítico, y de sus visiones del mundo.

Ante la cuestión de la colonialidad y su herencia, e incardinándonos en el debate abierto en el seno del feminismo no occidental, cabría preguntarse si el feminismo ha llegado a un momento histórico postcolonial. La violencia neocolonial y postcolonial sigue perpetuándose, especialmente contra las mujeres. Y es un hecho que en las sociedades en desarrollo o del Tercer Mundo, la marginalidad (pobreza y falta de acceso a la educación) se ve ocupada casi sistemáticamente por las mujeres. A juicio de la crítica chicana Emma Pérez, es imperativo crear un "Feminismo-del tercer-

\footnotetext{
${ }^{1}$ Walter Mignolo lo ha afirmado repetidamente desde su importante volumen, The Darker Side of Western Modernity (2003). Teóricos como Fredric Jameson, Enrique Dussel, Gloria Anzaldúa, Catherine Walsh, entre otros, trabajan también en esta línea.
} 
espacio-dentro-del-nacionalismo” (“Third-space feminism-within-nationalism”). ${ }^{2}$

Pérez aboga por la participación política activa de las mujeres, y en su modelo Foucaultiano, reclama que los cuerpos femeninos no sean regulados ni sometidos a “vigilancia” y "control” (surveillance) de modo que se quiebre la lógica del "panopticismo"3 como técnica de control social de las mujeres. Pérez señala que son el patriarcalismo, heterosexismo, las desigualdades de clase y sexo, la perpetuación y el refuerzo de los roles de género y el control ejercido por el estado-nación, las causas de la situación actual de las mujeres. Y ¿cómo pueden las mujeres a partir de la acción política crear el cambio social? Pérez propone el recurso al "imaginario de-colonial" desde una posición de "Tercer espacio" para llegar al empoderamiento de las mujeres y consecuentemente, a un ansiado cambio social.

Así pues, trabajar críticamente de manera de-colonial y transnacional -en el sentido de una multiplicidad de factores que afectan a varias sociedades- supone localizar esos puntos de fricción que separan a las mujeres de manera compleja del estado-nación. En este sentido se abren también nuevos horizontes de comparación en torno a la política de la raza que se hacen visibles en diferentes dominios de actividad que, a su vez, se hallan vinculados por el post-imperialismo. El trabajo ideológico de la nación se evidencia con sus tensiones raciales, jerarquizadoras y opresoras. Como Ann MacClintock (Imperial Leather, 1995) y Ann Laura Stoller (Race and the Education o Desire, 1995) han demostrado, cuestiones raciales y sexuales han sido tradicionalmente las "boundary makers of empire” (líneas de demarcación del imperio), y han traído consigo que en el trabajo contemporáneo de investigadoras y críticas haya cobrado gran expansión la investigación en torno a las mujeres, el cuerpo, los afectos y la sexualidad como puntos fundamentales de opresión imperial.

¿Qué podemos decir en un contexto transnacional del enorme esfuerzo de las mujeres para reconfigurar los límites de raza, nación e imperio? ¿Qué actitudes y qué práctica política han ejercido en momentos de crisis y de desmoronamiento del tejido social? Podríamos responder a estas preguntas con la inspiración del proyecto "decolonial” de Emma Pérez. A su juicio, ocupa un dominio “diferente, fragmentario, imaginado, no lineal y ateleológico” fuera del orden jerarquizador del estado y sus

\footnotetext{
${ }^{2}$ Recordemos que “Third space” está presente en la teorización de Homi Bhabha, quien aplica la teoría sociocultural al postcolonialismo, en la que hay "unequal and uneven forces of cultural representation.” Bhabha aspira a dar cuenta de la singularidad del individuo en tanto que "híbrido," compuesto de un entrecruzamiento de ideas y tradiciones (Bhabha, 1994: 55).

${ }^{3}$ El filósofo y político Jeremy Bentham (1748-1832) propuso el panóptico, un diseño de prisión circular con una torre en el centro para facilitar la plena visión y por tanto, la vigilancia de los prisioneros en las cárceles inglesas. Como es de sobra conocido, Michel Foucault, en Vigilar y Castigar (1975) retoma la idea para reflexionar sobre los instrumentos disciplinarios, demostrando de qué modo el poder hace uso de ellos en la sociedades modernas. El poder anónimo con el que se inviste el controlador de la prisión no hace sino mejorar y hacerse más efectivo y eficiente con el tiempo. El sujeto está, pues, bajo la lente constante del poder, que lo controla y amedrenta.
} 
servidumbres. Lo de-colonial sería subversivo y transgresor, quebrando la lógica binaria colonizador/colonizado, ciudadano/extranjero, blanco/negro....y contribuiría a deconstruir el imaginario social racializado en distintas sociedades. Tanto Emma Pérez como Gayatri Spivak aluden al proyecto de-colonial. En el caso de Spivak, desde su ensayo, enormemente influyente, “Can the subaltern speak?" su trabajo crítico ha estado siempre marcado por lo que ya enunciaba en 1983, "La cuestión es cómo evitar que el sujeto etnocéntrico se establezca a partir de definir selectivamente al Otro." ${ }^{4} \mathrm{La}$ intervención de Spivak con su "esencialismo estratégico" y la de tantas feministas que han seguido en su línea, ha llevado nuevas ideas y contra-críticas a la base de las formaciones del conocimiento colonial, desembocando en importantes trabajos antiimperialistas con una repercusión clara en la presencia de las mujeres como sujetos activos de saber y de potencial conocimiento insurgente.

Nancy Morejón y Jamaica Kincaid se proponen inscribir a la mujer negra en la historia entendida como "contra-narrativa" a la historia patriarcal, a la épica de la conquista, expansión, expolio y apropiación de la tierra y las culturas de América central y meridional por parte de la rapiña occidental. El trabajo de ambas comienza por una idiosincrática y personal estrategia de lectura.

Con nuestra aproximación a la obra de Morejón y Kincaid, aspiramos a demostrar que su producción de la subjetividad femenina negra y del espacio del Caribe, más que apelar a "unas atávicas puridades indígenas y afrodescendientes desde una especie de nativismo epistémico y culturalista” (Restrepo y Rojas, 2010: 221), se dirige hacia un proyecto de-colonial haciendo énfasis en la necesidad de acoger una diversidad de visiones en conflicto. La producción de una re-escritura de la historia, así como de una política del lugar para la región del Caribe que pone de manifiesto la diferencia colonial, y el papel esencial que concede al lenguaje en todas estas operaciones, responde a la idea de lo que Walter Mignolo denomina pensamiento fronterizo. Si, como afirma Mignolo, el pensamiento fronterizo emerge a partir del surgimiento y visibilidad de los intelectuales negros en el Caribe (Mignolo, 2000: 241), entonces la obra de Morejón y Kincaid es un claro exponente paradigmático de ese pensamiento fronterizo que debe darse a conocer y difundirse. Tanto Morejón como Kincaid, autoras poco conocidas y poco estudiadas conjuntamente, contribuyen a entender el Caribe anglo e hispanoparlante desde una perspectiva que, enmarcada en el proyecto de-colonial, nos presente la reconfiguración de los vínculos con otros legados coloniales que resultan esenciales para explicar cómo se produce ese espacio en el sistema globalizado de poder, y cuál es su relación con el pensamiento planetario decolonial.

Este trabajo se propone indagar en la manera en la que las ideas de la formación de la subjetividad y su relación con la identidad cultural que respaldan las teorías de la hibridación cultural, confluyen en la descentralización de la producción del

4 "The question is how to keep the ethnocentric subject from establishing itself by selectively defining the Other” (Spivak, 1988 [1983]: 292). 
conocimiento para el subalterno y la rearticulación de las relaciones entre lo global y lo local. La hibridación cultural, tal y como la plantea Homi Bhabha (1994) concibe los espacios entre-medio y los márgenes como lugares privilegiados desde donde poder intervenir en las narrativas de la raza y la nación impuestas por la modernidad. Las teorías de la hibridación, el planteamiento del "imaginario de-colonial”, y las estrategias de lectura transgresoras nos presentan una visión del mundo en la que caben otros mundos posibles, en los que se convive con la diferencia y la heterogeneidad de una manera alternativa a la que plantea el discurso hegemónico occidental. Todas estas cuestiones pretenden, a su vez, aportar nuevas visiones al debate entre lo local y lo global a la luz de elementos como: la experiencia de las mujeres con "identidades fronterizas", las diferencias culturales que tienen lugar en una misma localidad, la relación entre el lugar y las culturas híbridas en el contexto de la postcolonialidad, y en definitiva, la noción de cambio social y transformación cultural asociada al vínculo entre espacio y cultura.

\section{NANCY MOREJÓN: MUJERES Y AFROCUBANÍA}

Morejón (La Habana 1944-), licenciada en lengua y literatura francesas por la universidad de La Habana, y estudiosa de la obra de Nicolás Guillén, ensayista, investigadora y crítica, finalizó sus estudios con una tesis sobre el poeta martiniqués Aimé Césaire (1913-2008). Es considerada como una de las voces más relevantes de la poesía actual cubana. Su obra publicada incluye un importante corpus de poesía con más de veinte títulos, de entre los cuales cabe destacar Richard trajo su flauta y otros poemas (1967), Piedra pulida (1986) o Elogio y Paisaje (1997). Actualmente es la directora del Centro de Estudios del Caribe de la Casa de las Américas.

En este trabajo utilizamos la teoría feminista y postcolonial como óptica para aproximarnos al quehacer de Morejón y al de Jamaica Kincaid, apoyándonos en sus postulados en lo que es, ante todo, un análisis literario. También quisiéramos aclarar que utilizamos el concepto de mestizaje desde un paradigma afroantillano que no está necesariamente vinculado al discurso continental latinoamericanista con raíces en la cultura indígena. Dentro del contexto cubano, el mestizaje está sumergido en el imaginario cultural aportado por las personas negras en Cuba, específicamente en su cosmovisión, sus mitos, religiones, y modos de vida.

Con antecedentes en la narrativa escrita por hombres blancos o mulatos, y sin presencia propiamente en el panorama de la literatura nacional, la imagen de la mujer afrocubana fue definitivamente rescatada y redefinida por las poetas que salen a la luz después de la revolución. ${ }^{5}$ Con la Revolución cubana se imponen nuevas coordenadas

\footnotetext{
${ }^{5}$ Se ha señalado repetidamente que fue la etnóloga y escritora Lydia Cabrera (1899-1991) la responsable de situar a las mujeres afrocubanas en el panorama de la cultural nacional. Cabrera, investigadora en el acervo cultural de los yoruba estudió las estrategias narrativas arraigadas en los rituales, usos y costumbres de ese grupo humano. El método etnográfico fusionado con el 
sociales que afectan a la producción cultural e intelectual. En el panorama editorial cubano de los sesenta, predomina la poesía, y es ahí donde debemos situar a Nancy Morejón, perteneciente a la nueva generación de poetas que dan cuenta de nuevas transformaciones sociales. En 1970, once años después del triunfo de la revolución, Ildefonso Pereda Valdez publica un estudio sobre la poesía afrocubana en donde el único trabajo de una mujer que menciona es el de Morejón (Pereda Valdez, 1970).

Catherine Davies identifica dos acontecimientos que tuvieron un impacto en la poesía afrocubana en su totalidad y que fueron especialmente importantes en la poesía escrita por mujeres: El Año Internacional de la Mujer en 1975 y las campañas militares cubanas en Angola (1975-76) y Etiopía (1977-78) tuvieron un doble impacto en el ámbito artístico. Por una parte hubo un claro despertar feminista y por otra, una reafirmación de la identidad africana mediante la solidaridad política (Davies, 1997: 35).

La identidad de la mujer afrocubana se redefine en el presente con indudable protagonismo. Nancy Morejón, entre otras poetas de los 70, dedicará buena parte de su obra a estas cuestiones, si bien, como varias investigadoras han afirmado, los temas de raza y género en la poética de Morejón están subordinados a un discurso ideológico. Así, la toma de conciencia feminista, la proyección social de la mujer afrocubana, y la africanidad incipiente, aparecen intermitentemente en la obra de Morejón combinados con la presencia de la ideología dominante en la Cuba postrevolucionaria.

En el ámbito de la poesía, Nicolás Guillén (1902-1989) se convirtió en el representante más destacado de la cultura afrocubana. Según Morejón el poeta mulato y después el poeta negro, aspiraba a un "color cubano" abogando por la participación de todas las clases populares en la gestación de la nación (1982: 29). En su primer poemario, Motivos de son (1930), Guillén recoge el habla popular de las personas negras habaneras en una serie de poemas que escribió cuando tenía veintiocho años. El lenguaje utilizado por Guillén constituye un vínculo con el pasado ancestral, la recuperación de una identidad enterrada por siglos de colonización, y en el contexto neocolonial en el que fueron escritos, una afirmación de la independencia cultural. Morejón afirma que,

"Desde esta posición se aniquila el contexto que había sedimentado la expresión postmodernista: por lo que Motivos de son propone una vanguardia literaria que escapa los límites de una definición académica del término....Más que el hallazgo o la elección de un lenguaje, ...Motivos de son supone el aniquilamiento de toda la parafernalia verbal del Modernismo y sus secuelas” (1982:163).

Los poemas también se nutren de musicalidad africana tras la versificación

literario tuvo un papel central en su trabajo y lo trasladó al análisis de la situación de las mujeres en Cuba (véase Rodríguez-Mangual, 2004). 
rítmica, ya que son evidentes los rasgos que provienen de letras guarachas, pregones callejeros, comparsas, rumbas y claro, la cadencia del son. Tras la conquista formal de la introducción del son como ritmo poético en la tradición occidental escrita, Guillén inicia el proceso de descolonización cultural. A juicio de Morejón, Motivos es esencialmente una construcción mestiza, ya que "se conjugaron dos tradiciones: la oral y la escrita, la culta y la popular, una se integró en la otra” (1982: 46).

Como todo visionario socio-cultural, Guillén se anticipó al protagonismo que cobraría la mujer afrocubana al llegar a la conquista de su identidad en un poema titulado, “Mujer nueva” (Guillén, 2001 [1931]):

Con el círculo ecuatorial

Ceñido a la cintura como a un pequeño mundo

La negra, mujer nueva,

Avanza en su ligera bata de serpiente.

Coronada de palmas,

Como una diosa recién llegada,

Ella trae la palabra inédita,

El anca fuerte,

La voz, el diente, la mañana y el salto.

Chorro de sangre joven,

Bajo un pedazo de piel fresca,

Y el pie incansable

Para la pista profunda del tambor. (15)

Aunque en este poema siguen abundando las referencias sexuales, musicales, $\mathrm{y}$ animalísticas asociadas con la mujer afrocubana, hay en el un buen augurio, ya que la mujer surge triunfante e inmortal, armada con "la palabra inédita," o sea con la verdad. Así, con el cambio en el orden social a raíz de la Revolución cubana, la mujer toma las riendas de la poesía negra, eventualmente convirtiéndose en creadora y apropiándose de su historia. Es, de hecho, tal como implica el título del poema de Guillén una mujer 
nueva, o tal vez la de siempre que nunca fue reconocida y que ahora intenta romper con el molde impuesto. Morejón, al igual que Guillén, rechaza la etiqueta de lo afrocubano y cree en la existencia de una sola identidad cubana que no puede ser comprendida sin tomar en cuenta la influencia de la cultura negra.

Los trabajos de mujeres negras y mulatas no formarían parte de las "grandes narrativas” de la literatura cubana hasta después de la Revolución. Según Catherine Davies (1997), en la etapa inicial post-revolucionaria surgieron más oportunidades que nunca para que la mujer, antes marginada, publicara poesía. Muchas de ellas, jóvenes, sin experiencia literaria, expresaban, no solamente sentimientos íntimos, sino también sus percepciones sobre la comunidad que les rodeaba, la ciudad, y el panorama social a nivel nacional e internacional: "Escribían sobre la crisis de los misiles cubanos, sobre el papel de Cuba en África, entre otros acontecimientos históricos y revolucionarios. En este sentido, continuaban la larga tradición en la cual las mujeres cubanas escribían sobre la Revolución” (Davies, 1997: 137). ${ }^{6}$ La década de los setenta, momento en el que un cambio en las percepciones culturales identifican a la literatura cubana con las tradiciones caribeñas y tercermundistas (139), señalaría el momento preciso para que la nueva voz resonara con más fuerza.

Gran parte de la crítica ha señalado el punto de inflexión que dos de los poemas de Morejón dedicados a la mujer negra, suponen en su trayectoria creativa. Ambos, aparecidos en mitad de su carrera, "Mujer negra” y “Amo a mi amo" son dos composiciones esenciales que definen bien cómo Morejón entiende la genealogía y el legado de las mujeres afrocaribeñas en su propio devenir mujer escritora.

“Mujer negra” (1967) es un poema de corte épico dedicado al tránsito de esclavos y esclavas en los barcos esclavistas desde distintos puntos de África, cruzando el Atlántico, hacia el nuevo mundo. La voz de una mujer negra, comprada como esclava, arriba a Cuba para trabajar en la plantación, en el trabajo doméstico, vejada y abusada sexualmente, dio a luz hijos para el amo, y finalmente se rebeló hasta llegar a ser sujeto de su propia historia. La primera estrofa se abre con el recuerdo ancestral, con la dialéctica de la memoria y el olvido, y la costa africana grabada en la memoria de la esclava, así como su lengua, de la que nunca pudo separarse.

Cada una de las estrofas presenta una etapa diferente en el devenir de la mujer esclava, desde la mujer africana trasplantada como esclava a la isla, la esclava trabajadora, la esclava rebelde, hasta la revolucionaria. Como los lectores y las lectoras puede apreciar, cada etapa está conectada generacionalmente con la evolución de las esclavas en la sociedad cubana desde el siglo XIX:

I. Todavía huelo la espuma del mar que me hicieron atravesar.

6 “They wrote about the Cuban missile crisis, the literacy campaign, Cuba’s involvement in Africa, and other historical and revolutionary events. In this sense, they were continuing the long tradition in which Cuban women wrote about the nation” (Davies,1997: 137). 
La noche, no puedo recordarla.

Pero no olvido al primer alcatraz que divisé.

Altas, las nubes, como inocentes testigos presenciales.

Acaso no he olvidado ni mi costa perdida, ni mi lengua ancestral.

Me dejaron aquí y aquí he vivido.

Y porque trabajé como una bestia,

Aquí volví a nacer.

A cuanta epopeya mandinga intenté recurrir.

Me rebelé (2002: 200)

En la segunda estrofa, la mujer negra ha sido vendida, ha trabajado como esclava doméstica, cosiendo y atendiendo las tareas del hogar. Como era habitual, vejada y violada por su señor, dio a luz un hijo "sin nombre" que le fue arrebatado. Su trabajo incansable en los campos, la violencia física y los malos tratos, la vida en suspenso en un barracón, le hicieron cobrar conciencia de la necesidad de sublevarse. Fue suficiente confrontar la muerte de otros muchos de los esclavos africanos que habían corrido peor suerte que ella, si bien, no llegó a contemplar la posibilidad de retornar a sus raíces:

IV. En esta misma tierra toqué la sangre húmeda

Y los huesos podridos de muchos otros,

Traídos a ella, o no, igual que yo.

Ya nunca más imaginé el camino a Guinea.

¿Era a Guinea? ¿A Benin? ¿Era a Madagascar? ¿O a Cabo Verde?

Trabajé mucho más (2002: 200)

Morejón se hace eco del esfuerzo ímprobo de la esclava que "construí mi mundo" (2002: 201) en el lugar de su cautiverio. A partir de su toma de conciencia y su lucha por la liberación, vivió en el palenque, lugar de los asentamientos de los cimarrones. En los palenques vivían los negros fugitivos, en los márgenes de las ciudades y fuera de la ley. Lograron la libertad huyendo armados a sitios montañosos, y muchos de ellos fundaron enclaves con una población importante. Según su relato, la esclava se unió a las tropas de Antonio Maceo (1845-1896) -hijo de mestizo venezolano y mulata 
liberta-, figura clave del movimiento independentista cubano del XIX, allí batalló junto a los hombres y demás esclavos huidos, e hizo suya la causa de su nueva tierra. El poema se cierra como sigue:

V. Mi real independencia fue el palenque

Y cabalgué entre las tropas de Maceo.

Sólo un siglo más tarde,

Junto a mis descendientes,

Desde una azul montaña,

Bajé de la Sierra

VI. para acabar con capitales y usureros,

Con generales y burgueses.

Ahora soy: sólo hoy tenemos y creamos.

Nada nos es ajeno.

Nuestra la tierra.

Nuestros el mar y el cielo.

Nuestras la magia y la quimera..

Iguales míos, aquí los veo bailar

Alrededor del árbol que plantamos para el comunismo.

Su pródiga madera ya resuena. (2002: 202)

Finalmente, Antonio Maceo fue héroe nacional, y los soldados y cimarrones que lucharon en su ejército, participaron de la liberación de Cuba. En el programa independentista, Maceo y sus colaboradores llevaban como máxima la independencia de la isla y la liberación de los esclavos, algo que parecía utópico, pero que llegó a estar muy cerca. 
Este es un poema que recorre la historia y que transita hacia la creación de la conciencia nacional cubana, en el que una mujer negra anónima se erige en símbolo de la independencia nacional cubana y de la voz de la conciencia colectiva.

Uno de los poemas más antologizados de Morejón es, sin duda, “Amo a mi amo,” en el que continúa con la temática esclavista, centrada en esta ocasión en el sometimiento sexual de la esclava negra. El poema se abre con una retórica sensual de la que la autora se sirve para tratar, de manera ambivalente, de la subyugación sexual de la esclava, así como del propio sometimiento del amo a sus favores. En medio de un clima de sensualidad encendida, la esclava recorre los sentidos, vista, tacto y oído, en el que se detiene para evidenciar la asimetría de poder, lengua, y música de la metrópoli y de la colonia:

Taño la vihuela y de su garganta salían

Coplas sonoras, como nacidas de la garganta de Manrique.

Yo querría haber oído una marímbula sonar.

Amo su boca roja, fina,

Desde donde van saliendo palabras

Que no alcanzo a descifrar

Todavía. Mi lengua para él ya no es la suya.

Y la seda del tiempo hecha trizas. (2002: 196)

Las coplas -como las de Manrique, unidad estrófica fundamental en la lírica hispana- habrán de ser sustituidas por la marímbula, instrumento musical del Caribe, extendido también por África y otros lugares del continente de América meridional que dio lugar a un ritmo cubano que se desarrolló en la provincia de Guantánamo, el changüí, que toma carta de naturaleza a partir de la combinación de cuatro instrumentos musicales autóctonos: marímbula, bongo, tres y güiro.

El amo habla sin cesar de Dios a la esclava, y la esclava maldice sin parar. Obligada a usar la lengua del opresor, no encuentra alternativa para recuperar su identidad perdida. Su existencia presente es una mistificación, incomunicada y aislada, sólo escucha el ruido del tambor violento y las campanas (que, sin duda, doblan por su muerte): 
Maldigo

Esta bata de muselina que me ha impuesto,

Estos encajes vanos que despiadado me endilgó,

Estos quehaceres para mi en el atardecer sin girasoles,

Esta lengua abigarradamente hostil que no mastico;

Estos senos de piedra que no pueden ni siquiera amamantarlo,

Este vientre rajado por su látigo inmemorial; este maldito corazón.

Amo a mi amo pero todas las noches,

Cuando atravieso la vereda florida hacia el cañaveral

Donde a hurtadilla hemos hecho el amor,

Me veo cuchillo en mano, me veo cuchillo en mano desollándole como a una res

Sin culpa.

Ensordecedores toques de tambor ya no me dejan

Oír ni sus quebrantos, ni sus quejas,

Las campanas me llaman... (2002: 198)

Como hemos mostrado en "Mujer Negra” y “Amo a mi amo", a través de un proceso de autoconocimiento y legitimización del pasado afro-femenino, Morejón se hace eco de las historias personales y colectivas de las mujeres de color por medio de la impronta artística que ejercen como sujetos de la historia y como narradoras. Utilizando los temas del recuerdo, el tributo a las antepasadas femeninas, la vindicación de las imágenes afro-femeninas en las grandes narrativas de la identidad nacional, así como la veneración de lo materno, la poeta deconstruye los estereotipos afrofemeninos para proyectar una imagen del yo y del Otro re-construida, re-habilitada dentro de un marco de literatura de resistencia. 
En el urgente desmantelamiento de los códigos paternalistas, desarticulando y reconstruyendo el pasado para redefinir la identidad de las mujeres afrocubanas en el presente, Morejón trasciende los parámetros misóginos del negrismo. ${ }^{7}$

Con el acto de su auto-inscripción en la poesía, Morejón y sus colegas de generación, se sitúan en la vanguardia de la creación dotando a la palabra poética del poder de construir y alterar la realidad. En su lucha por crear un sujeto lírico que sea representativo de la experiencia afrocubana en Cuba y que quede incardinado en el subconsciente cultural, Morejón se alza como una de las voces poéticas más influyentes de la poesía postrevolucionaria cubana.

\section{JAMAICA KINCAID: FABULACIONES DE LA VIDA ENTRE DOS MUNDOS}

No puede comprenderse la literatura caribeña contemporánea sin tener en cuenta el exilio y la diáspora afrocaribeña. Marie-Hélène Laforest señala:

"El Caribe es esencialmente un archipiélago diaspórico. Su geografía física y humana revela la historia de sus movimientos, transiciones, y desplazamientos. Habitados por pueblos 'en exilio permanente' que han sido diseminados por diversas latitudes en las Américas y a lo largo de varios continentes, el Caribe es el epítome de lo que James Clifford ha propuesto en su importante ensayo, 'Diásporas', como el rasgo definitorio y fundamental de las diásporas, 'la práctica de residir durante un tiempo prolongado fuera del hogar'” (2000: 2). ${ }^{8}$

${ }^{7}$ El negrismo es un estilo artístico que subraya las características primitivas y exóticas de la cultura panafricana y que alcanzó popularidad en el momento de la vanguardia europea a comienzos del siglo XX. Esta moda pasajera que influyó en los círculos artísticos europeos, no obstante, inspira el proceso de legitimación racial en Cuba entre la propia intelligentsia cubana. Las expresiones artísticas afrocubanas encontraron puntos de contacto con la soberanía cultural de los EEUU. Si bien en Cuba el negrismo comenzó a hacerse sentir en el momento en el que los primeros esclavos africanos fueron conducidos a la isla y se encuentra profundamente arraigado en la rica poesía popular anónima cubana. La tradición oral africana, así como las canciones rituales de las religiones de origen africano están en la base de este movimiento. La esencia del negrismo en Cuba lleva consigo una búsqueda profunda de identidad nacional y un encuentro fructífero con su pasado.

8 "The Caribbean is essentially a diasporic archipelago. Its physical and human geography accounts for its history of movement, transition, and displacement. Inhabited by peoples in 'ancestral exile' who have successively been dispersed through various latitudes within the Americas and across different continents, the Caribbean epitomizes what James Clifford has proposed in his seminal essay, 'Diasporas', as the main and indispensable characteristic of diasporas, that is, the 'practice of long-term dwelling away from home’” (Laforest, 2000: 2). 
Jamaica Kincaid (1949-) se fue de Antigua para convertirse en enfermera. La enfermería, al igual que la enseñanza, es una profesión que garantiza un status social y económico a la mujer en el Caribe. Su falta de interés hacia ella le llevó al mundo de la fotografía y, posteriormente, al periodismo y la escritura. La emigración de Lucy, protagonista de la novela homónima, también es voluntaria pero no se siente a gusto en el país anfitrión y tiene que adaptarse a una sociedad opulenta y radicalmente diferente a la suya donde todo es "oscuro" y "frío" como la noche de enero en la que comienza la narración.

Jamaica Kincaid da un paso más en el desarrollo de la autobiografía contemporánea. Fragmenta la forma y la historia simbolizando así su propio yo escindido. El estilo se rompe en innumerables frases que se repiten, los recuerdos se entremezclan y la narración autobiográfica se divide en una serie de libros que cuentan la historia personal y familiar, de forma que la visión parcial que cada uno de ellos aporta configura las piezas de este particular universo de la escritora caribeña. Prácticamente la totalidad de la narrativa de Kincaid puede entenderse como ficción autobiográfica. Mediante las diversas formas con las que presenta su yo-autobiográfico Kincaid va desarrollando el tema central de su narrativa: el proceso de separación madre - hija como indispensable para lograr su madurez, simbolizando la figura materna, por su parte, a la metrópoli colonial.

A pesar de las diferencias entre los diversos tipos de autobiografía (textos de memorias, diarios, textos a caballo entre la realidad y la ficción, etc) hay en todas ellas dos elementos constantes que Kincaid también incorpora: el deseo expreso de vivir como cada uno elija y la crítica tácita o explícita de las condiciones externas que delimitan o anulan la libertad de elección personal. Ambos elementos representan los dos puntos donde la autobiografía y la ficción negra se vuelven inseparables y se explican la una a la otra.

Otras muchas características de la autobiografía negra están presentes en la obra de Kincaid: realismo y autenticidad histórica en la representación de la violencia, injusticia, pobreza, negación de aspiraciones o incluso de la cultura -recordemos la descripción del proceso de desculturización que aparece en A Small Place (1988) o la imposición de un modelo cultural y educativo victoriano que reflejan "Girl" y Annie John (1985)-; presentación de héroes solitarios que luchan por comprenderse a sí mismos y comprender la realidad que les rodea; creación de una imagen de disparate y locura cercana al teatro del absurdo, locura de la realidad externa al protagonista que conforma a los personajes de la literatura negra: reconociendo una situación como absurda e imprevisible se adaptan a ella para sobrevivir, convirtiéndose en maestros del disfraz físico y psicológico. Kincaid ha reconocido en numerosas entrevistas que, del mismo modo que lo hace Lucy, al iniciar una nueva vida lejos de su familia, se inventa a si misma estudiando fotografía y cambiando su nombre, lo cual le permite empezar a escribir : "Simplemente hice que mi presente fuese diferente de mi pasado...la decisión 
crucial fue no comunicarme con mi familia” (Bonetti, 1992: 125). ${ }^{9}$

Detrás de este juego de máscaras y cambios de personalidad, aparentemente absurdo, se esconde la búsqueda de una estructura vital e histórica y el fuerte deseo de ordenar los recuerdos caóticos y violentos, en ocasiones modelando una vida en torno al viaje, el peregrinaje, la odisea, siempre hacia el norte, como único medio de preservar su humanidad y su integridad, camino de la oscuridad a la luz, camino hacia liberación del yo mediante la palabra y el conocimiento.

Elaine Potter Richardson (Jamaica Kincaid) nació el 25 de mayo de 1949 en St. John, capital de la isla de Antigua. Antigua es una pequeña isla con una superficie de $280 \mathrm{Km} 2$. Lo que fue una sociedad agraria con una economía basada en la caña de azúcar, durante la vida de Kincaid, ha pasado a depender de la industria turística que da empleo a más de la mitad de la población pero, a su vez, ha cambiado determinadas formas de vida: "La Antigua que yo conocí, la Antigua en la que crecí, no es la Antigua que tú, turista, podrás ver ahora. Aquella Antigua ya no existe” (1988: 23) ${ }^{10}$ avisa una indignada Kincaid al turista, nuevo colonizador de nuestros días.

Si nos remontamos a su historia colonial, es interesante recordar que en 1493 Antigua fue visitada y bautizada por Cristóbal Colón, personaje duramente criticado por Annie John, para ser colonizada en el siglo XVII por los ingleses quienes importaron de África esclavos negros para las grandes plantaciones. Los orígenes esclavos de Annie y Lucy nos ayudarán a comprender el fuerte sentimiento de rebeldía y resistencia de ambos personajes. Antigua consiguió su independencia completa en 1981 pero su gobierno se ha caracterizado por la corrupción y los frecuentes escándalos que Kincaid denuncia en A Small Place y que afectan a la economía, la sanidad y la educación.

Jamaica pasó su infancia y adolescencia en St. John’s. Su familia era de clase trabajadora - “éramos gente pobre, normal” -"we were poor, ordinary people” - y su madre Annie Richardson Drew, que tuvo en su momento una intensa actividad de oposición al régimen corrupto de Bird, pertenecía a una familia de campesinos de la isla de Dominica. Su abuelos, una india caribeña y un policía mitad escocés mitad africano, servirían de inspiración para los personajes centrales de The Autobiography of My Mother (1996). Kincaid conoció a su padre biológico cuando era adulta y le describe como un tipo de hombre característico de Antigua, orgulloso de haber engendrado un gran número de hijos por los que nunca tomó ningún interés: "Es un ejemplo de hombre antillano típico: quiero decir, tienen hijos, pero nunca parecen tener

9 "I just made my present different from my past ...the crucial thing was that I would not communicate with my family” (Bonetti, 1992: 125).

10 "The Antigua that I knew, the Antigua in which I grew up, is not the Antigua you, a tourist, would see now. That Antigua no longer exists” (1988: 23). 
interés real por ellos” (1990, 131). ${ }^{11}$ Aunque de religión metodista, su familia practicaba el Obeah u obia, un sistema de creencias que mezcla espiritualidad y ritos de brujería, magia y curanderismo - toda la obra de Kincaid está llena de referencias al Obeah, especialmente frecuentes en Annie John (1985).

En el colegio fue una alumna precoz y entre sus temas favoritos estaban la historia y la botánica. Ambos temas influirán en gran medida en su escritura: la reescritura de la Historia del Caribe, la esclavitud y el colonialismo y, recientemente, la relación entre botánica, jardinería e imperio. Sin embargo, su talento no fue reconocido ni por su familia, a quienes sólo parecía preocupar el futuro de sus hermanos, ni por sus profesores, debido, en cierto modo, a un temperamento crítico y rebelde, representados fielmente por Annie John y Lucy.

A los trece años tiene que abandonar el colegio para atender a sus hermanos, algo que le disgustó profundamente como deja bien claro en My Brother (1998):

"A los trece, a los catorce, a los quince, no me gustó. No me gustaban los otros hijos de mi madre, por entonces no me gustaba mi madre; me gustaban los libros, me gustaba leer libros...Mi hermano pequeño tenía dos años cuando por primera vez lo dejaron a mi cargo" (1998: 128). ${ }^{12}$

Lo cual supone el primer paso en el proceso de separación emocional de la figura materna con la que hasta entonces se había sentido profundamente unida. Las complejas, ambiguas y muy difíciles relaciones entre madre e hija aparecen reflejadas, entre otros, en el relato corto "My Mother," incluido en la colección At the Bottom of the River; (1983) en el que Kincaid anticipa elementos biográficos de su madre que desarrollará en The Autobiography of My Mother (1996) dando sensación de continuidad y permanencia. La relación amor-odio, dependencia-emancipación, marcará la infancia, adolescencia, juventud, madurez y toda la obra de Kincaid:

"De inmediato, después de desearle la muerte a mi madre y de ver el dolor que le causó, lo lamenté y derramé tantas lágrimas como para anegar la tierra a mi alrededor. De pie junto a mi madre le rogué que me perdonara, y lo hice con tanto arrepentimiento, que se apiadó de mi, me besó, y me puso la cabeza sobre su pecho para que descansara” (1997 [1983]: 53). ${ }^{13}$

\footnotetext{
11 "He's sort of typical of West Indian men: I mean, they have children, but they never seem to connect themselves with these children” (1990: 131).

12 "At thirteen, at fourteen, at fifteen, I did not like this, I did not like my mother's other children, 1 did not like my mother then; I liked books, I liked reading books . . . My youngest brother was two years old when one day he was left in my charge” (1998: 128).

13 "Immediately on wishing my mother dead and seeing the pain it caused her, I was sorry and cried so many tears that all the earth around me was drenched. Standing before my mother, I
} 
Lo que en un principio fue una relación marcada por la ternura, la comprensión y la protección, con la llegada de Jamaica a la adolescencia se convierte en una lucha feroz contra la influencia de una madre que quiere convertirla en una joven educada según las pautas que la mentalidad victoriana, heredada del pasado y de la clase media que les rodea, aplica a las mujeres: mujeres pasivas y sometidas al patriarcado. Así, en "Girl”, relato muy breve, y hermoso ejemplo de prosa poética, en forma de monólogo interno, reproduce las instrucciones de la madre a la hija sobre cómo comportarse adecuadamente tratando de evitar que su hija cometa sus propios errores y permitiéndonos leer entre líneas el abuso sexual históricamente sufrido por las mujeres negras:

“Así es como se pone la mesa para el té; así es como se pone la mesa para la cena; así es como se pone la mesa para un invitado importante; así es como se pone la mesa para la comida; así es como se pone la mesa para el desayuno; así es como se comporta una en presencia de hombres a quienes no conoce bien, y de ese modo, les es imposible reconocer de inmediato al tipo de mujer ligera cuyos pasos te advertí que nunca deberías seguir" (1997 [1983]: 4). ${ }^{14}$

Kincaid encontrará en la lectura y los libros la reafirmación que necesita a medida que aumente su separación de la madre y su sentimiento de aislamiento. Al igual que en el caso del joven Richard Wright el "hambre" de leer, la llevará a leer no sólo a los grandes autores de la literatura inglesa (Milton, Shakespeare, Dickens, Charlotte Brontë) sino también la Biblia y la Historia. Los libros -Jane Eyre, entre otrosimpulsan una creciente rebelión contra el colonialismo británico que queda así asociado a la figura materna. La biblioteca se convierte para ella en su paraíso particular y ello justifica su indignación cuando vuelve a Antigua después de una prolongada ausencia y encuentra que sigue en ruinas después de haber sido destruida en un terremoto. En A Small Place Jamaica Kincaid expone su pensamiento político y la biblioteca se convierte entonces en el símbolo de la corrupción y destrucción a la que tanto el poder colonial como el gobierno poscolonial están llevando al país ante la actitud pasiva de su propio pueblo:

"Es buena cosa que hayas traído tus libros contigo, pues no se puede simplemente ir a la biblioteca y sacar alguno en préstamo. Antigua solía tener una biblioteca espléndida, pero con el terremoto, el edificio de la

begged her forgiveness, and I begged so earnestly that she took pity on me, kissing my face and placing my head on her bosom to rest” (1997 [1983]: 53).

14 "This is how you set a table for tea; this is how you set a table for dinner; this is how you set a table for an important guest; this is how you set a table for lunch; this is how you set a table for breakfast; this is how to behave in the presence of men who don't know you very well, and this way they won't recognize immediately the slut I have warned you against becoming” (1997 [1983]: 4). 
biblioteca quedó dañado...Has traído tus libros contigo y entre ellos hay uno de esos libros nuevos de historia económica, uno de esos libros que explican cómo Occidente se enriqueció" (1988: 8-9). ${ }^{15}$

A los diecisiete años Kincaid abandona Antigua hacia los Estados Unidos para trabajar como "au pair" y permanece durante tres años con la familia Arlen. Su estancia entre ellos aparece magistralmente descrita en Lucy. Jamaica, de ser una joven provinciana de las colonias, se convierte en una mujer negra americana, independiente y apasionada por la fotografía, la historia, la literatura y la jardinería.

La publicación de A Small Place y las duras críticas contra el gobierno que el libro contenía fueron la causa de que se le prohibiera la entrada en el país durante varios años. En 1986, veinte años después de su partida, pudo volver a la isla y reconciliarse con su madre a la que no había visto desde entonces. La ambivalencia de sus relaciones con la madre se proyectan en su relación con la isla y son un tema constante en su escritura y en sus entrevistas. En la actualidad, vive en Vermont, sin embargo sus lazos con Antigua permanecen tan intensos como cuando vivía allí manteniendo esa fragmentación que caracteriza su vida y su ficción : "Cuando estoy en Vermont, siento que mi hogar está en Antigua; cuando estoy en Antigua, siento que mi hogar está en Vermont" (1999: 37). ${ }^{16}$

El tema central de Annie John y Lucy son las relaciones tensas y ambivalentes madre/hija. Hay prueba de ello en las numerosas entrevistas concedidas por Kincaid. Selwyn R. Cudjoe recoge algunas de las declaraciones más significativas en las que la escritora reflexiona sobre el tema central de su escritura y la búsqueda de los orígenes de su inspiración creadora:

"Bueno, creo que fue un problema de falta de sintonía en la adolescencia, porque ahora nos llevamos muy bien. Es posible que como seres humanos no nos gustemos en absoluto, pero como madre e hija, nos queremos. Creo que si tuviese que conocer a mi madre en un contexto determinado, no me gustaría. Es una mujer extraordinaria, no hay duda de eso (...) Mi segundo libro, Annie John, trata de la relación de una niña con su madre porque el terreno abonado para la creación en mi caso es mi madre. Cuando escribo algunas cosas uso la voz de mi madre porque me gusta. Me gusta cómo ve las cosas, supongo que si quisieras saber si es feminista, te diría que sí. Pienso que no tendría vida creativa ni interés real

15 "It's a good thing that you brought your own books with you, for you couldn't just go to the library and have a splendid library, but in the Earthquake the library building was damaged ... You have brought your own books with you, and among them is one of those new books about economic history, one of those books explaining how the West got rich" (1988: 8-9).

16 "When I am in Vermont, home is Antigua; when I am in Antigua, home is Vermont" (1999: 37). 
en el arte sin mi madre. Es, sin lugar a dudas, mi 'terreno abonado"” (1990: 30). ${ }^{17}$

Pero, detrás de esta relación, se oculta el segundo gran tema en Kincaid: la identificación de la figura materna con la metrópoli, la "madre colonizadora". La separación de ambas será un proceso doloroso y traumatizante.

Laura Niesen de Abruna comenta como detrás de la narración autobiográfica de Annie John, susceptible de ser analizada desde una perspectiva psicoanalítica-feminista hay no sólo la historia de una joven y sus relaciones con la madre y la pequeña isla que es su patria sino que también está la historia de cómo y por qué estos conflictos se ubican en una isla del Caribe recientemente liberada del dominio Británico.

Moira Ferguson (1993), una de las más importantes estudiosas de Jamaica Kincaid, afirma que Kincaid representa una fase de transición entre la Antigua colonial y la postcolonial y los cambios en la balanza del poder que se producen como consecuencia de los cambios históricos. Kincaid escribe en los años 80 sobre la Antigua de los 50 cuando la isla ha obtenido una independencia todavía parcial.

Condicionada por la relación con la figura materna y los conflictos de crecer siendo mujer en un país colonizado, Kincaid pone de relieve la influencia de la maquinaria imperial que desde Cristóbal Colón llega a nuestros días. Mediante la máscara de Annie John y de Lucy, Kincaid lucha contra la marginalidad impuesta por la raza, la clase y el género siguiendo las pautas trazadas por antecesoras como Mary Wollstonecraft, Anne Hart Gilbert, Elizabeth Hart Thwaites, Jane Austen y Jean Rhys.

Esta relación entre lo biológico y lo político, entre lo privado y lo público, es un tema constante entre las autoras caribeñas de nuestros días que escriben en sociedades de extrema diversidad y divididas entre la influencia occidental y la africana provocando un "clima de inseguridad en las relaciones humanas paralelo al clima de inestabilidad política y social, especialmente entre mujeres y mujeres, hombres y mujeres y madres e hijas”(Niesen 1990: 34).

La fragmentación de yo es mucho más dramática cuando la madre se representa como colaboradora con el poder colonial. Lucy empieza donde Annie John termina

17 "Well, I hope it's an adolescent dislike, because now we get a long very well. lt's possible that as human beings we don't like each other at all but that as a mother and daughter we love each other. I think that if I were to meet my mother in a certain context, I wouldn't like her. She's an extraordinary person, there's no question about that (...) My second book, Annie John, is about a girl's relationship with her mother because the fertile soil of my creative life is my mother. When I write, in some things I use my mother's voice, because I like my mother's voice. I like the way she sees things. In that way, I suppose that it you wanted to say it was feminist, it can only be true. I feel it would have no creative life or no real interest in art without my mother. lt's really my “fertile soil” (1990: 30). 
pero Lucy no ha ido a Inglaterra sino a Estados Unidos, su eterno rival, y allí es donde se produce en la protagonista la tensión-dialéctica entre el deseo y la lucha contra la llamada materna (Lucy nunca abre las cartas que recibe de Antigua).

Una vez lejos de Antigua, Lucy, el mismo personaje que Annie John, pero con diferente nombre, versión más madura del yo autobiográfico de Kincaid, es capaz de no abrir las cartas que recibe de su madre pero ya ha aprendido que nunca podrá prescindir de ella, que su vínculo es tan fuerte que se asemeja a una cárcel:

"Mi pasado era mi madre; podía escuchar su voz....me hablaba en un idioma que cualquier mujer podría comprender...había gastado tanto tiempo diciendo que no quería ser como mi madre - Era mi madre. Y ahora, ahora me daba cuenta de cómo tras unos pocos débiles intentos de trazar una línea entre las dos, su respuesta siempre fue 'Puedes huir pero no puedes escapar al hecho de que hoy tu madre, mi sangre corre por tus venas, estuviste nueve meses en mi interior" (1994: 90). ${ }^{18}$

El yo rebelde de ambos personajes, Annie y Lucy, no sólo se manifiesta frente a la figura materna sino que se proyecta en la visión de la historia y del mundo que les rodea y así aparece el yo político de Kincaid, que identifica el dominio materno con la autoridad colonial británica y tiene sus precedentes en la actitud de resistencia que las mujeres esclavas tuvieron que adoptar frente a los amos blancos. Desde el comienzo de su carrera literaria Kincaid no ha dejado de denunciar el genocidio y la pérdida de memoria histórica de los pueblos colonizados. Uno de los capítulos más interesantes de Annie John es el titulado “Columbus in Chains”. La figura histórica de Cristóbal Colón es utilizada como símbolo de las contradicciones de la educación colonial.

Cuando Kincaid iba al colegio algunas de las materias fundamentales del currículo eran historia, literatura y cultura de Europa, especialmente Británica (Mistron 1999). La rebelión de Annie puede ser interpretada como la rebelión contra un sistema que no reconoce la historia, la cultura y los valores del pueblo afrocaribeño. El castigo que Annie sufre por su rebeldía es significativo: "Como castigo añadido, me mandaron que copiase los Libros I y II de Paradise Lost de John Milton” (1985: 82). ${ }^{19}$

Otra manifestación del yo autobiográfico fragmentado de la autora se produce en el dualismo existente entre el yo colectivo africano de Annie y el yo exiliado,

18 "My past was my mother; I could hear her voice . . . she spoke to me in language anyone female could understand . . . I had spent so much time saying I did not want to be like my mother that I missed the whole story: I was not like my mother -I was my mother. And I could see now why, to the few feeble attempts I made to draw a line between us, her reply always was 'You can run away, but you cannot escape the fact that I am your mother, my blood runs in you, I carried you for nine months inside me'” (1994: 90).

19 "As an added punishment, I was ordered to copy Books I and II of Paradise Lost by John Milton” (1985: 82). 
emigrante y ajeno al sistema, en definitiva, de Lucy que se enfrenta a un mundo nuevo que intentará desposeerla de su yo histórico, de su memoria histórica. Del mismo modo que es imposible deshacer el vínculo con la madre, no se puede romper con el pasado africano, simbolizado por la abuela y por el ritual obeah, un tipo de espiritualidad procedente de las religiones africanas que está presente en todos los actos de la vida cotidiana tanto para curar como para ejercer efectos negativos en los enemigos.

Varios elementos se conjugan, desde un punto de vista formal, para representar al yo autobiográfico de Kincaid. En primer lugar, la unificación del yo narrador, yo autobiográfico y yo real de forma que lo que nos podía parecer la descripción del proceso de maduración de una adolescente se convierte en algo inseparable de su biografía tal y como Kincaid se ha encargado de hacer saber en las numerosas entrevistas en las que ha explicado detalladamente sus propias vivencias.

Finalmente, quisiera destacar una vez más que Annie John y Lucy se complementan perfectamente y forman junto con A Small Place una trilogía que, en palabras de Marie-Hélène Laforest, "delinea el viaje de Kincaid desde su adolescencia infeliz en Antigua hasta convertirse en una mujer adulta y segura de sí misma en el mundo norteamericano" (2000: 45). ${ }^{20}$

Pero este viaje simboliza además el recorrido de un pueblo en busca de su madurez histórica. Si, como dice Germaine Brée (1988), los psicólogos y sociólogos encuentran que es predominante en la mujer la conciencia de una identidad colectiva, toda la obra autobiográfica de Jamaica Kincaid está inspirada por un sentido visionario del destino colectivo de su pueblo, lo cual la acerca notablemente a sus precursoras, las grandes autobiógrafas negras, y la incluye en la nueva generación de escritoras afrocaribeñas que han vivido el desplazamiento y el exilio en primera persona. Por ello, Carol B. Davies (1994) considera el trabajo de Kincaid como literatura de resistencia en términos de raza, género, clase y lugar. Esta crítica analiza la generación de Kincaid como compuesta por aquellas escritoras que fueron testigos de la transición de todas las islas del Caribe desde una ideología colonial a una independiente. Todas ellas contemplaron de niñas los comienzos del lenguaje de la independencia, se dieron cuenta de adultas de que había nuevas formas de imperialismo y colonización y experimentaron lo doloroso que había sido crecer saludando al sol con banderitas frente a la presencia de algún miembro de la familia real inglesa.

La necesidad de encontrar y defender un espacio propio, una habitación propia, ha marcado profundamente la vida y la obra de Kincaid y ello explica en gran medida esos sentimientos de individualismo, resistencia e ira tan intensos, que no duda en proyectar contra su propia madre de cuya “colonización” es la primera en protegerse.

La relación con la madre se convierte entonces en la gran obsesión y, por tanto, en

20 "trace Kincaid's journey from an unhappy adolescent in Antigua to a self-assured adult in the U. S. World” (2000: 45). 
el tema central y casi exclusivo de su obra narrativa hasta tal punto que borra definitivamente las ya difusas líneas de separación entre ficción, autobiografía y vida.

Donna C. Stanton (1984) ha analizado el "matrilinealismo" que prevalece en la obra de algunas escritoras como Hellman, Kingston y Angelou: la madre simboliza tanto el origen, que es el mismo y diferente a la vez, como el "espejo" donde se reflejan las posibilidades del ser en proceso de evolución. Donna Perry, por su parte, cita a aquellas escritoras como Paule Marshall y Toni Morrison, que han inmortalizado "luchas con éxito entre madres e hijas en la ficción y la autobiografía” (Perry, 1990: $73)^{21}$ y añade que para la mujer de color la madre y las mujeres de la familia y la comunidad representan fuerza, confianza en sí mismas, historia personal y colectiva y grandes dosis de realidad.

Para muchas de estas autoras la abuela primero y después la madre son dos figuras de referencia fundamentales en la infancia y adolescencia, pero Kincaid da un paso más en la revelación de su yo interno al describirnos el doloroso proceso de separación de esa madre caribeña tan llena de fuerza quien, a su vez, ha sido víctima de un sistema político que la ha aniquilado como ser humano -algo que Kincaid no nos desvelará hasta The Autobiography of my Mother (1996).

La ruptura es tan dura que Kincaid necesitará mucho tiempo para superarlo en la vida real -pasó veinte años sin ver a su madre- y varias obras en la ficción para recomponer su fragmentado yo autobiográfico. Definitivamente Kincaid rompe las barreras entre lo vivido y lo escrito, entre vida y creación literaria, aportando además un testimonio central sobre la situación postcolonial de Antigua.

El importante trabajo crítico de Emma Pérez, con su articulación del imaginario de-colonial, plantea deconstruir y re-escribir la historia de occidente, una historia colonial que habrá de confrontar su propia narrativa en oposición y que se propone contrarrestar el círculo vicioso destructivo del patriarcado. Es muy posible que en las Humanidades contemporáneas, una disciplina de historia intelectual y social informada por la historia transnacional de las ideas que se ocupase de su devenir y trascendiese la división entre formas de la élite y formas subalternas, centrada en la crítica a la raza, la nación y el imperio fuese pedagógicamente efectiva para el presente y el futuro. En el ámbito de la crítica y la creación y en el de la pedagogía activa, la centralidad de la obra de autoras como Kincaid y Morejón, marginales hasta ayer mismo y hoy sujetos de su propia historia y relatoras de la de sus pueblos, de sus antepasadas femeninas, del sustrato mítico-espiritual de sus sociedades, no hace sino evidenciar que feminismo y proyecto de-colonial, son parte de un mismo impulso para reconceptualizar el universo sociosimbólico de las futuras generaciones.

21 “successful struggles between mothers and daughters in fiction and autobiography” (1990: 73). 


\section{REFERENCIAS BIBLIOGRÁFICAS}

BHABHA, HOMI K. (1994): The Location of Culture. London: Routledge.

BONETTI, KAY (1992): An Interview with Jamaica Kincaid. Missouri Review 15(2),123-142 .

BRÉE, GERMAINE (1988): Autogynography. En, Olney, J., ed., Studies in Autobiography, 171-179. Oxford: Oxford University Press.

CORDONES-COOK, Juana M. (2009): Soltando amarras y memorias. Mundo y poesía de Nancy Morejón. Santiago de Chile: Cuarto Propio.

CUDJOE, SELWYN R.(1990): Jamaica Kincaid and the Modemist Project: An Interview. En Cudjoe, S.R., ed., Caribbean Women Writers. Calaloux Publications: Wellesley, M A.

DAVIES, CAROL B. (1994): Black Women, Writing and Identity. London: Routledge.

DAVIES, CATHERINE (1997): A Place in the sun. Woman writers of 20th century Cuba. London: Zed Books.

FEAL, ROSEMARY GEISDORFER (1996): Poetas Afrohispánicas y la Política de la identidad, http://sincronia.cucsh.udg.mx/feal.html, 11/20/2015.

FERGUSON, MOIRA (1993): Colonialism and Gender Relations. From Mary Wollstonecraft to Jamaica Kincaid. New York: Columbia University Press.

GUILLÉN, NICOLÁS (2001 [1931]): Sóngoro cosongo. Alicante: Biblioteca Virtual Miguel de Cervantes. http://www.cervantesvirtual.com/obra/songoro-cosongo-1931--0/

KINCAID, JAMAICA (1985) Annie John. New York: The Noonday Press.

- (1988): A Small Place. London: Virago Press.

_ (1994): Lucy. London: Picador.

- (1996): Autobiography of my Mother. London: Vintage.

_ (1997 [1983]): My Mother. En, At the Bottom of the River. London: Vintage.

_ (1997 [1983]): Girl. En, At the Bottom of the River. London: Vintage.

_ (1998): My Brother. New York: Farrar, Straus \& Giroux.

KORNWEILER, KAREN RUTH (2010): Daisy Rubiera Castillos' "Reyitaa”: Mujer Negra” from Objectified Symbol to Empowered Subject. Letras Hispanas, 7, 67-79.

LAFOREST, MARIE-HÉLENE (2000): Diasporic Encounters. Remapping the Caribbean. Napoli: Liguori.

WALTER (2000): Local Histories/Global Designs: Coloniality, Subaltern Knowledge and Border Thinking. Princeton, NJ: Princeton University Press.

- (2003): The Darker Side of Western Modernity. Durham, NC: Duke University Press. 
MISTRON, DEBORAH (1999): Understanding Jamaica Kincaid's Annie John. London: Greenwood Press.

MOREJÓN, NANCY (1982): Nación y mestizaje en Nicolás Guillén. La Habana: Ed. Unión.

- (2002): Mirar Adentro. Looking Within. Selected Poems, 1954-2000. Trans. \& Ed. Cordones-Cook, Juana M. Detroit: Wayne State University Press.

NIESEN DE ABRUNA, LAURA (1990): Twentieth-Century Women Writers from the English-Speaking Caribbean. En, Cudjoe, S.R., ed., Caribbean Women Writers. Calaloux Publications: Wellesley, MA.

- (1991): Family Connections: Mother and Mother Country in the Fiction of Jean Rhys and Jamaica Kincaid. En Nasta, S., ed., Motherlands: Black Women's Writing from Africa, the Caribbean and South Asia, 273-275. London: The Women's Press.

PARAVISINI-GEBERT, LIZABETH (1999). Jamaica Kincaid: A Critical Companion. London: Greenwood Press.

PEREDA VALDEZ, ILDEFONSO (1970): Lo negro y lo mulato en la poesía cubana. Montevideo: Ediciones Ciudadela.

PÉREZ, EMMA (1999): The Decolonial Imaginary. Writing Chicanas into History. Bloomington, IN: Indiana University Press.

PERRY, DONNA (1990): Initiation in Jamaica Kincaid's Annie John. En Cudjoe, S.R., ed., Caribbean Women Writers. Calaloux Publications: Wellesley, MA.

RENK, KATHLEEN J. (1999): Caribbean Shadows and Victorian Ghosts. Women's Writing and Decolonization. Charlottesville, VA: University Press of Virginia.

RESTREPO, EDUARDO \& EDUARDO ROJAS (2010): Inflexión decolonial. Fuentes, conceptos y cuestionamientos. Instituto de Estudios Sociales y Culturales Pensar. U. Javeriana, Colombia: Ed. Universidad de Cauca.

RODRÍGUEZ-MANGUAL, EDNA R. (2004): Lydia Cabrera and the Construction of an Afro-Cuban Identity. Chapel Hill, NC: University of North Carolina Press.

SPIVAK, GAYATRI CHAKRAVORTY (1988): Can the Subaltern Speak?. En Nelson, C., Grossberg, L., eds., Marxism and the Interpretation of Culture, 271313. Chicago, IL: University of Chicago Press.

STANTON, DOMNA C. (1984): Autogynography: Is the Subject Different?. En Stanton, D.C., ed., The Female Autograph: Theory and Practice of Autobiography from the Tenth to the Twentieth Century. Chicago: University of Chicago Press.

ZULOAGA ROBLEDO, JUAN MANUEL (2014): Nicolás Guillén y Nancy Morejón: Mujer lasciva y provocadora versus mujer épica y funcional. Cronopio, Edición 47, 24 enero, 2014. http://www.revistacronopio.com/?p=11983.

WILLIAMS, CLAUDETTE (2011): Nancy Morejón y la historia de la mujer cubana. Revista Iberoamericana, LXXVII (235), 425-439. 